\title{
PERAWATAN SALURAN AKAR INSISIVUS CENTRALIS RAHANG BAWAH PADA ANAK CLEIDOCRANIAL DYSPLASIA
}

\author{
(ROOT CANAL TREATMENT OF THE LOWER CENTAL INCICORS \\ IN PATIENT WITH CLEIDOCRANIAL DYSPLASIA)
}

\author{
Harun Achmad*, Sri Ramadany **, Hendrastuti Handayani* \\ *Staf Pengajar Bagian Ilmu Kedokteran Gigi Anak, \\ Fakultas Kedokteran Gigi, Universitas Hasanuddin \\ **Staf Pengajar Bagian Ilmu Kesehatan Masyarakat, \\ Fakultas kedokteran, Universitas Hasanuddin Makassar Indonesia \\ E-mail: harunachmad@yahoo.com
}

\begin{abstract}
Cleidocranial dysplasia is a syndrome characterized by an applasia/hypoplasia of the clavicles, craniofacial malformations, and the supernumerary teeth. The aetiology and pathogenesis of this syndrom is not known dificult. It is a manifestation of dominant or recessive derivates. Occurs in the same frequency between men and women, and no racial predilection. The aim of the case report was to give descriptions for the root canal treatment of the lower permanent cental incicors in patient with Cleidocranial dysplasia. A 5 years old boy came to the Pediatric Dental Department, Faculty of Dentistry of Hasanuddin University with a complaint of pain in the lower incisors, the clinical diagnosis of the teeth was irreversible pulpitis. Almost all the erupted teeth expierenced anatomical anomalies. On panoramic radiographs abnormalities appear in the form of delayed Eruption and multiple supernumerary teeth. The patient was planned to get root canal treatments of the permanent lower central incisors. It can be conluded, the treatment for the root canal of the permanent lower central incisors was highly important for this patient to maintain the masticatory function and the aesthetic function.
\end{abstract}

Key words: cleidocranial dysplasia, delayed eruption, endodontic

\begin{abstract}
Abstrak
Cleidocranial dysplasia adalah sindrom yang ditandai oleh aplasia/hipoplasia klavikula dengan karakteristik malformasi kraniofasial dan adanya gigi berlebih (gigi supernumerary). Etiologi dan patogenesis sindroma ini belum diketahui secara pasti. Penyakit ini merupakan suatu manifestasi dominan atau resesif turunan. Terjadi dalam frekuensi yang sama antara pria dan wanita, serta tidak ada predileksi ras. Tujuan penulisan ini adalah untuk menjelaskan perawatan saluran akar gigi insisivus sentralis rahang bawah pada pasien dengan Cleidocranial dysplasia. Kasus; Seorang anak laki-laki, umur 5 tahun datang ke Klinik Bagian Ilmu Kedokteran Gigi Anak FKG UNHAS dengan keluhan rasa sakit pada gigi anterior rahang bawah, diagnosa klinis pada kedua gigi insisivus sentralis rahang bawah adalah pulpitis irreversible. Hampir semua gigi yang telah erupsi mengalami anomali secara anatomis. Pada gambaran radiografi panoramik, tampak kelainan berupa erupsi beberapa gigi yang tertunda (delayed eruption) dan terdapat beberapa gigi berlebih (supernumerary teeth). Pada pasien ini dilakukan perawatan saluran akar pada kedua gigi Insisivus sentralis permanen rahang bawah. Sebagai kesimpulan, perawatan saluran akar pada kedua gigi Insisivus sentralis rahang bawah pada pasien sangat penting dilakukan untuk mempertahankan fungsi pengunyahan serta memperbaiki nilai estetik.
\end{abstract}

Kata kunci: cleidocranial dysplasia, erupsi tertunda, perawatan saluran akar

\section{PENDAHULUAN}

Cleidocranial dysplasia juga dikenal dengan Cleidocranial dysostosis, Osteodental dysplasia, atau Marie-Sainton Disease adalah suatu kelainan tulang yang disebabkan oleh mutasi gen CBFA1 (core binding factor alpha 1) /RUNX2 pada lengan pendek kromosom 6p21. Dalam keadaan normal, gen ini menuntun diferensiasi osteoblas dan pembentukan tulang yang tepat. Mutasi gen pada Cleidocra- 
nial dysplasia bersifat autosomal dominant inheritances dan sebanyak $40 \%$ kasus disebabkan oleh mutasi gen yang spontan. ${ }^{1}$ Insidensi Cleidocranial dysplasia diseluruh dunia sekitar 1:1.000.000 tanpa membedakan jenis kelamin dan ras. Cleidocranial dysplasia tidak hanya melibatkan tulang intramembran seperti klavikula, tulang kranial, dan tulang pipi. Cleidocranial dysplasia juga melibatkan osifikasi endokhondral dan memberikan gambaran kelainan struktur skeletal yang menyeluruh. ${ }^{1}$

Penderita cleidocranial dysplasia biasanya memiliki postur tubuh lebih pendek, kepala yang lebar dan pendek (brachiepalic, tulang frontal, parietal, dan occipital yang menonjol (bossing), hipertelorism (jarak interorbital yang terlalu lebar), serta memiliki jembatan hidung (bridge nose) yang lebar dan datar. Penderita ini juga memiliki kemampuan menggerakkan bahunya ke depan karena hipoplasia atau aplasia klavikula baik sebagian maupun keseluruhan. Penderita cleidocranial dysplasia tidak mengalami gangguan intelegensi. Pada umumnya penderita Cleidocranial dysplasia memiliki maksila yang kurang berkembang dan mandibula cenderung prognatik, serta palatum yang tinggi dan sempit. Manifestasi pada gigi geligi biasanya berupa persistensi gigi desidui, kegagalan dan keterlambatan erupsi gigi permanen, dan multiple supernumerary teeth. ${ }^{2-5}$

Tanaka et al., Silvia et al. ${ }^{9}$ menemukan bahwa anak yang menderita Cleidocranial dysplasia dengan kondisi gigi yang abnormal memiliki riwayat keluarga dengan kondisi gigi geligi yang abnormal pula. Salah satu karakteristik gigi geligi pada penderita Cleidocranial dysplasia adalah persistensi gigi desidui. Keadaan ini diduga disebabkan oleh resorpsi akar gigi desidui yang sebagian besar tidak terjadi atau terlambat pada penderita Cleidocranial dysplasia. Pada penderita ini pembentukan dental lamina dan erupsi gigi desidui normal. ${ }^{6}$

Keterlambatan dan kegagalan erupsi gigi permanen sering terjadi pada penderita Cleidocranial dysplasia. Gigi yang paling sering erupsi spontan adalah molar pertama dan insisivus permanen mandibula. Molar kedua permanen hanya $75 \%$ yang erupsi pada penderita Cleidocranial dysplasia. Insisivus sentral maksila sering mengalami kegagalan erupsi dan biasanya menjadi alasan pasien mencari perawatan untuk menangani masalah dentalnya. ${ }^{6}$ Winter menjelaskan bahwa gigi permanen yang tidak diawali oleh adanya gigi desidui memiliki kemungkinan yang lebih besar untuk erupsi. Tipisya tulang yang melindungi perkembangan tooth buds juga dapat meningkatkan kemungkinan erupsi gigi. Alasan kegagalan erupsi gigi permanen pada penderita Cleidocranial dysplasia belum dimengerti dengan baik. Melalui gambaran radiografi penderita Cleidocranial dysplasia, tulang alveolar terlihat lebih striated dan hiperostotik. Keadaan ini diduga sebagai salah satu penyebab impaksi gigi permanen. ${ }^{3}$ Keterlambatan erupsi juga sering dihubungkan dengan kurangnya sementum seluler pada akar gigi.

Karakteristik gigi geligi lainnya pada penderita Cleidocranial dysplasia adalah supernumerary teeth yang banyak dan impkasi. Gigi ini kebanyakan terdapat di regio anterior maksila dan mandibula. Sejumlah supernumerary teeth pernah ditemukan hingga lebih dari 60 gigi. Bentuk supernumerary teeth biasanya mirip dengan gigi tetangganya tetapi memiliki kecacatan bentuk dengan akar yang berbentuk kaitan (hook) menyebabkan kesulitan saat pengekstaksian. Adanya supernumerary teeth yang tidak erupsi serta bentuk akar dan mahkota yang menyimpang juga dianggap sebagai penyebab terhalangnya erupsi gigi permanen. Gigi permanen yang tidak erupsi dapat mengakibatkan pembentukan kista yang kemudian akan menyebabkan terjadinya destruksi tulang dan fraktur patologi. ${ }^{8}$

Adanya multiple supernumerary teeth dapat menyebabkan obstruksi mekanis dan merupakan faktor utama impaksi gigi permanen. ${ }^{1}$ Menurut I Golan et al. prevalensi supernumerary teeth dan kegagalan erupsi pada penderita ini lebih dari $93,5 \%{ }^{7}$

\section{KASUS}

Seorang anak laki-laki, umur 15 tahun datang ke Klinik Bagian Ilmu Kedokteran Gigi Anak FKG UNHAS dengan keluhan rasa sakit pada gigi insisivus sentralis rahang bawah. Data rekam medik pasien dari bagian Dokter Spesialis Anak menunjukkan bahwa pasien didiagnosa Hydrocephalus, dan memiliki kelainan sistemik pada ginjal dan jantung (defek septum ventrikel). Pada gambaran ektra oral terlihat kepala yang lebih lebar dan menonjol, jarak inter orbital yang jauh, memiliki jembatan hidung (lebih lebar dan datar), tinggi maksilla yang pendek dan selalu menggerakkan kedua bahunya kedepan (Gambar 1). Pada pemeriksaan intra oral terlihat hanya beberapa gigi yang erupsi dan hampir semua gigi yang telah erupsi mengalami anomali secara antomis. Pada rahang atas tampak gigi 11, 52, 54, 62, 64 yang telah erupsi, sedangkan pada rahang bawah terlihat gigi-geligi yang erupsi adalah gigi 36, 34, $33,32,31,41,42,43,44,45,46$. Diagnosa pada kedua gigi insisivus sentralis rahang bawah adalah Pulpitis irreversible. Pada gambaran radiografi panoramik (Gambar 2), tampak kelainan berupa erupsi beberapa gigi yang tertunda (delayed eruption) sehingga menyebabkan gigi-geligi tidak erupsi dengan 
sempurna dan juga terdapat beberapa gigi berlebih (multiple supernumerary teeth), terlihat adanya gigi impaksi, dan ukuran maksila yang sempit serta mandibula yang lebih prognatik. Pasien tidak mengalami gangguan kecerdasan dan tidak ada gangguan komunikasi. Berdasarkan keadaan sistemik, kondisi fisik serta kelainan yang kami temukan pada pemeriksaan ekstra oral maupun intra oral dapat kami simpulkan bahwa pasien mengalami kelainan yang disebut sebagai Cleidocranial dysplasia. Keadaan umum pasien baik dan pasien memperlihatkan tingkah laku yang positif pada saat kunjungan pertama dan pada saat pemeriksaan. Pasien direncanakan untuk dilakukan perawatan saluran akar pada kedua gigi Insisivus sentralis permanen rahang bawah.

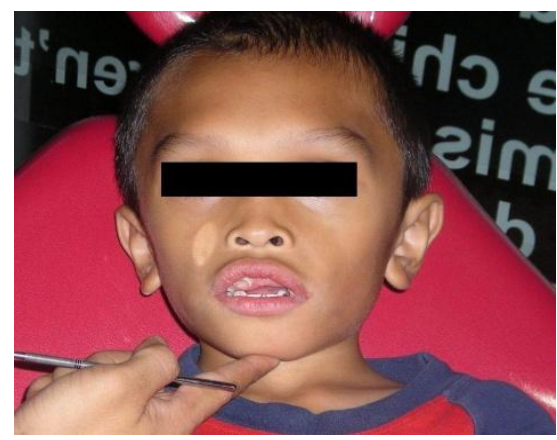

Gambar 1. Profil pasien kepala yang lebih lebar dan pendek

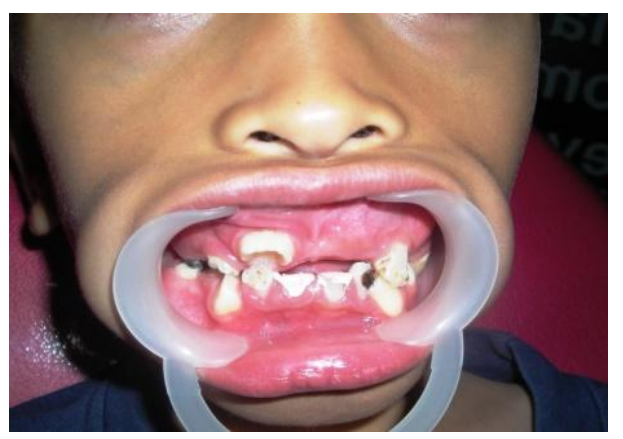

Gambar 2. Pemeriksaan intra oral tampak gigi insisivus sentralis kiri rahang atas yang tidak erupsi, dan terlihat klainan bentuk pada gigi lain yang telah erupsi
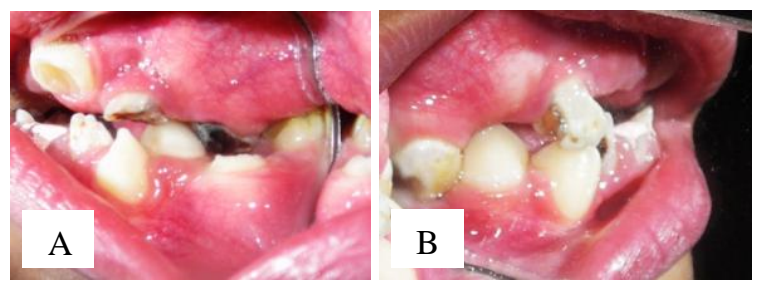

Gambar 3. A dan B terlihat hanya beberapa gigi yang erupsi dan gigi-geligi mengalami kelainan bentuk

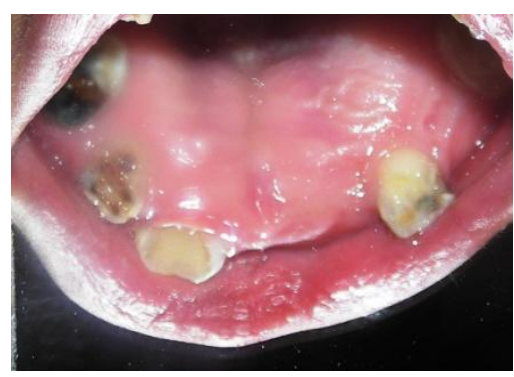

Gambar 4. Tampak hanya beberapa gigi yang erupsi yaitu gigi $11,52,54,62,64$

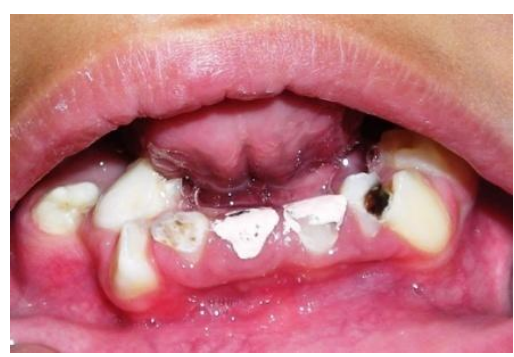

Gambar 5. Pada rahang bawah terlihat tidak semua gigi erupsi dengan sempurna, hanya beberapa gigi yang erupsi yaitu gigi 36, 34, 33, 32, 31, 41, $42,43,44,45,46$

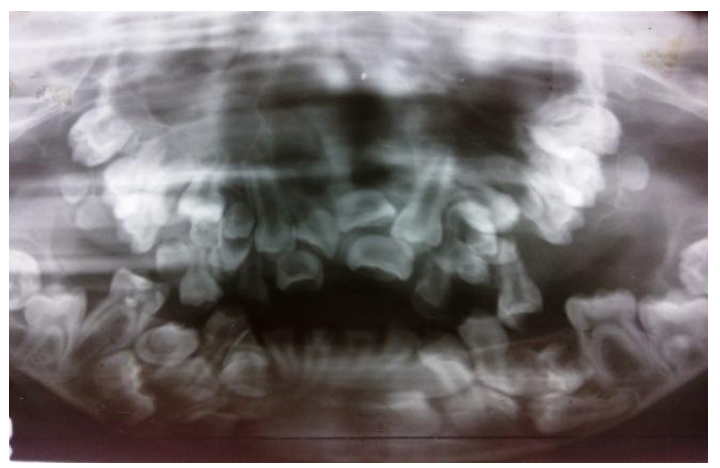

Gambar 6. Radiografi panoramik terllihat adanya Multipe supernumerary teeth, gigi dengan delayed eruption, dan gigi impaksi

\section{PENATALAKSANAAN KASUS}

Setelah semua evaluasi dilakukan termasuk hasil pemeriksaan klinis dan radiologi secara lengkap pada kunjungan pertama kemudian dibuat rencana perawatan berikutnya berupa perawatan saluran akar untuk gigi Insisivus sentralis permanen rahang bawah. Pada kunjungan kedua dilakukan penembusan saluran dan foto panjang kerja, kemudian dilakukan reaming hingga file ukuran 90, foto panjang kerja, sterilisasi, dan kemudian ditutup dengan tambalan sementara. Pada kunjungan ketiga dan empat dilakukan kontrol sterilisasi. Pada kunjungan ke lima dilakukan obturasi saluran akar dengan kondensasi lateral (Gambar 7). Kunjungan ke enam dilakukan 
pemotongan guttap, kemudian dilakukan preparasi mahkota, selanjutnya dilakukan insersi pasak fabricated. Pada tahap ini dibutuhkan retainer untuk crown sehingga retainer dibentuk dengan menggunakan komposit. Setelah retainer terbentuk, dilakukan pencetakan rahang atas dan rahang bawah, kemudian pemasangan provisory crown. Pada kunjungan selanjutnya dilakukan insersi crown, dan pada kunjungan terakhir dilakukan kontrol.
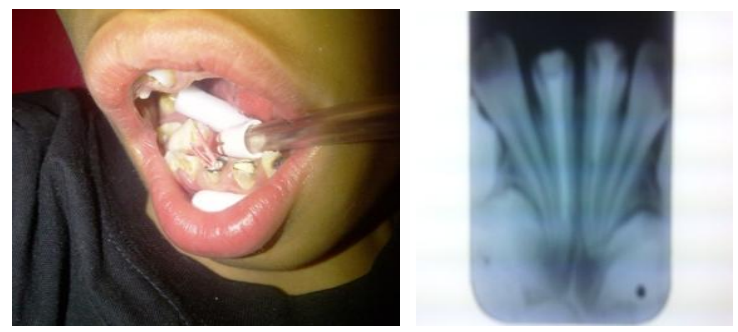

Gambar 7. A dan B Pengisian saluran akar dengan pemasangan guttap dan gambaran radiografis pengisian saluran akar

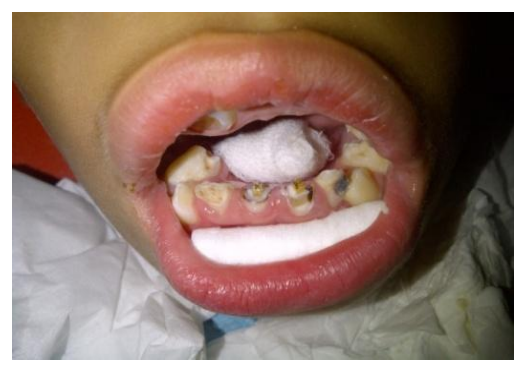

Gambar 8. Post saluran akar dengan pasak fabricated

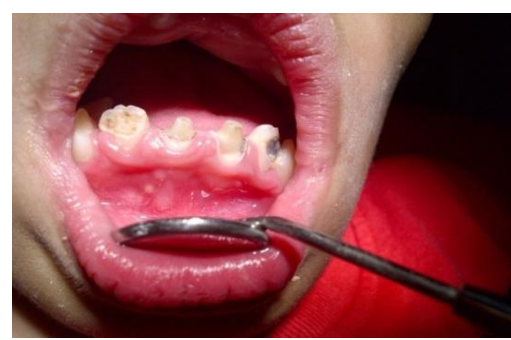

Gambar 9. Retainer di bangun dengan komposit

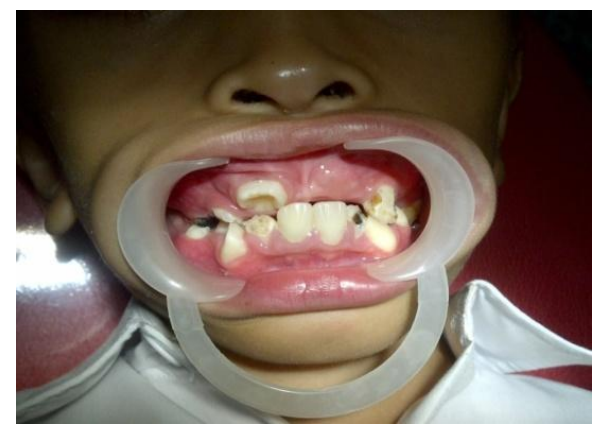

Gambar 10. Gigi Insisivus sentralis permanen setelah pemasangan Crown akrilik

\section{PEMBAHASAN}

Adanya kelainan bentuk dan pertumbuhan gigi pada pasien dengan Cleidocranial dysplasia dapat mempengaruhi estetik wajah dan mengarah ke permasalahan klinis. Sehingga dilakukan beberapa tindakan untuk menangani permasalahan tersebut. Perawatan pertama yang dilakukan pada pasien ini disesuaikan dengan keluhan utamanya pada kunjungan awal yaitu perawatan saluran akar pada kedua gigi Insisivus sentralis permanen rahang bawah. Pertimbangan dilakukannya perawatan ini karena diperkirakan tidak ada lagi gigi pengganti, sehingga harus dipertahankan tetap dalam soketnya dan mengembalikan fungsi mastikasi dan estetiknya.

Perawatan saluran akar adalah suatu usaha menyelamatkan gigi terhadap tindakan pencabutan agar gigi dapat bertahan dalam socket. Dalam perawatan ini harus diketahui prinsip-prinsip ilmu saluran akar secara benar yaitu pengetahuan mendiagnosis, cara merestorasi jaringan gigi yang hilang dan mempertahankan sisa jaringan, sehingga gigi tersebut dapat bertahan selama mungkin di dalam mulut dan menghindari tindakan pencabutan agar gigi dapat bertahan dalam soketnya sehingga dapat memperlambat resorbsi tulang alveolar gigi terkait. Keuntungan secara psikologis yang diperoleh adalah gigi dapat bertahan secara alamiah. Pasien tetap memiliki gigi asli dalam kedaan sehat, karena gigi dapat berfungsi seperti semula, dan gigi dapat dipakai sebagai tumpuan gigi tiruan lepasan. Dalam setiap melakukan perawatan saluran akar, prinsip prinsip perawatan saluran akar harus selalu diperhatikan, yaitu teknik asepsis, akses langsung saluran akar, pembersihan dan pembentukan saluran akar, pengisian saluran akar, dan pembuatan restorasi (penambalan, pembuatan onlay atau mahkota) yang benar, sehingga didapatkan jaringan periodondal yang sehat. Umumnya kualitas restorasi sangat bergantung pada tiga faktor, yaitu klinisi/dokter gigi, bahan restorasi, laboratorium gigi, dan pasien. Tetapi dari keempat faktor penyebab kegagalan tersebut, yang sangat memegang peranan adalah faktor klinisi/dokter gigi tersebut. Sedang bahan restorasi adalah faktor terakhir kegagalan restorasi (penambalan, pembuatan onlay atau mahkota).

Tujuan prosudur restorasi adalah membentuk gigi seperti semula sehingga dapat berfungsi kembali, memberi kekuatan untuk menahan daya kunyah atau daya lain seperti trauma, clenching, atau bruxism. Selain itu juga perlindungan terhadap proses karies, dan sedapat mungkin dapat digunakan sebagai penjangkaran gigi tiruan lepasan atau cekat.

Sebagai kesimpulan, pasien Cleidocranial dysplasia dengan permasalahan mastikasi dan estetik me- 
merlukan perawatan dengan saksama dan teratur. Salah satu perawatan yang dilakukan untuk mengembalikan fungsi tersebut serta mempertahankan sisa gigi dalam soket nya adalah dengan melakukan perawatan saluran akar. Dengan perawatan ini maka fungsi mastikasi, dan nilai estetik pada pasien dapat dipertahankan. Setelah dilakukan perawatan, pasien merasa lebih nyaman dan merasa puas dengan hasil perawatannya. Akan tetapi perawatan terhadap masalah dental lainnya harus dilanjutkan untuk memperoleh keberhasilan perawatan secara menyeluruh oleh berbagai disiplin ilmu kedokteran gigi, seperti pada penanganan gigi impaksi, penggunaan protesa dan perawatan jaringan periodontal, namun tetap dalam pengawasan dokter gigi anak.

\section{Daftar Pustaka}

1. Golan I, Baumert U, Hrala BP, Mubig D. Dentomaxillofacial variability of Cleidocranial dysplasia; clinicoradiological presentation and systematic review. Denmaxilofacial Radiology 2003; 32: 34754.
2. Petropoulos VC, Balshi TJ, Balshi SF, Wolfinger GJ. Treatment of a patient with Cleidocranial dysplasia using osseointegrated implants: a patient report. Int J Oral Maxillofacial Implants 2004; 19: 282-7.

3. Daskalogiannakis J, Piedade L, Lindholm TC, Sandor GKB, Carmichael RP. Cleidocranial dysplasia: 2 generations of management. J Can Dent Assoc 2006; 72(4): 337-42.

4. Mendoza-Londono R, Lee B. Cleidocranial dysplasia. January 6 2006. (www.genetest.org).

5. Lopez BSG, Solalinde CO, Ito TK, Carillo EL, Solalindo EO. Cleidocranial dysplasia: report of a family. J Oral Sci 2004; 46(4): 259-66.

6. Kolokhita OG, Papadopoulou AK. Cleidocranial dysplasia: etiology, clinical characteristic, diagnostic information and treatment approach. Hell Orthod Rev 2008; 11: 21-33.

7. Golan I, Baumert U, Hrala BP, Mubig D. Dentomaxillofacial variability of Cleidocranial dys-plasia; clinicoradiological presentation and systematic review. Denmaxilofacial radiology 2003; 32: 347-54.

8. Vojvodic D, Komar D, Zabarovic D. Prosthetic Rehabilitation of a patient with Cleidocranial dysostosis: a clinical report. Acta Stomatol Croat 2007; 412(3): 237-8. 